occurring as an intercurrent affection in a patient suffering from tuberculous disease of the hip-joint, appeared to have a beneficial and curative influence on the tuberculous condition.

A boy, aged seven years, was under treatment for tuberculous hip disease with a sinus discharging on the posteroesternal aspect of the thigh when he had an attack of scarlet fever. He was removed to the isolation hospital. A large abscess had now formed on the anterior aspect of the thigh in the region of the hip and it was necessary to operate. Under an anæsthetic the abscess was incised and a gauze drain was put in. For the next two or three days the boy lay in a very precarious condition and it was doubtful if he would recover. However, the fever abated and he began to improve. As convalescence progressed the tuberculous condition got very much better and by the time con. valescence was established the tuberculous sinuses had healed. The change in his general condition was also very marked. At first he was thin and pale, but during convalescence he put on weight and when discharged was quite fat and rosy. He was also able to run about and had no discharging sinuses, a state of affairs which had not been his for over two years.

The question is whether the cure of the tuberculous condition was influenced by the scarlet fever. I have not had an opportunity of watching another case similar to the above. of course, there is always the chance of the cure occurring at that time being a mere coincidence, but I must say I have never yet seen a tuberculous condition take such a rapid turn for the better. - I am, Sirs, yours faithfully,

August 25th, 1906.

JOHN ALLAN, M.B.

\section{HAMATOGENOUS ALBUMINURIA.}

\section{To the Editors of ThE LANCET.}

SIRS,-I was interested to read Dr. R. Hingston Fox's article on this subject in THE LANCET of August 25th, p. 497. Since the publication of Sir A. E. Wright's observation on the influence of calcium lactate in so-called "functional" albuminuria I have tested the point repeatedly. In four cases which I suspected to be of this type the albuminuria was readily controlled by the drug, but in cases with other evidence of kidney disease calcium lactate had no obvious effect. I therefore agree with Dr. Fox that it is a useful diagnostic test and that the primary cause of the albuminuria is the state of the blood. But I am inclined to think that he rather belittles the disturbance of the cardio-vascular mechanism in these cases. The great tendency to fainting, especially on standing for some time, and the appearance of albuminuria only after getting up, strongly suggest a lax condition of the vaso-motor system which, failing to compensate for the effect of gravity, allows both cerebral anæmia and back pressure on the kidney to occur. These considerations have led me to use digitalis as well as calcium lactate and, so far as I can judge, the effect has been good.-I am, Sirs, yours faithfully,

Finsbury-square, E.C., Sept. 3rd, 1906.

$$
\text { W. LANGDON BroWN. }
$$

\section{THE GERMAN LANGUAGE AND MEDICAL MEN.}

To the Editors of THe LANCET.

SIRS,-I have received several letters from your readers which indicate that there is some difficulty in obtaining Messrs. Fiedler and Sandbach's little book. With your permission I will give the specification for order through a printer: "A First German Course for Science Students," by H. G. Fiedler and F. E. Sandibach. Alex, Moring, Limited, the De la More Press, 32, George-street, Hanover-square. 1906. 2s. 6d. net. I am, Sirs, yours faithfully,

Sept. 3rd, 1906 ARTHUR LOXTON.

\section{SANITATION AT ST. MORITZ.}

\section{To the Editors of THE LANCET.}

SIRS, - In answer to an inquiry by Dr. T. W. Parkinson on this subject ${ }^{1}$ there appeared in THE LANCET on Sept. 16th, 1905, p. 854, a letter signed by Dr. J. F. Holland and Dr. P. Gredig which stated with regard to the winter season

\footnotetext{
1 The LanCeT, August 14th, 1905, p. 553
}

1904-05 as follows: (1) that the main drainage was sound (2) that the public health was in no way endangered; and (3) that the chief main drainage was then carried right ont into the river Inn, whence it issued with torrential force.

The wish was no doubt father to the thought. It seems, however, on inquiry, (1) that the experts referred to in the letter had (as the authorities frankly admit) recommended that all drainage into the lake should be stopped and another system adopted, thereby showing that in their opinion the existing main system was faulty; (2) that complaints of suppurative tonsillitis and like ailments were extraordinarily numerous during the winter in question, and when septic illness occurs in an antiseptic air and the drains are subse. quently ordered to be remodeled it is more likely that the public health was endangered than not, though actual typhoid fever, diphtheria, \&c., were absent; and (3) that (as the authorities likewise admit) the new main system instead of being complete on Sept. 16th, 1905, as stated in the letter, was not complete in March, 1906, or expected to be so till later.

The fact is that St. Moritz had rapidly outgrown its sani. tary system, and though the authorities assure us that they are doing their hest to put things right the publication of a certificate by first-class independent professional experts that the entire system, both main and subsidiary, is now perfected and up-to-date would be more conclusive than any other assurance. At present the only promise obtainable (in March last) is that the work when complete will be certified by an authority, but by whom and whether or where the certificate will be published is not stated nor whether it will include the subsidiary system.

I trust I have said enough to show that there is nothing unreasonable in now asking for the publication of this certificate in THE LANCET, especially as it is over a year since the London Sanitary Protection Association reported confidentially on the matter and suggested the necessary alterations. Such a step would at once remove the uneasiness to which Dr. Parkinson referred, and would be in the best interests of the place to which many of us owe much. I am, Sirs, yours faithfully,

H. CAMPBELI JENKINS,

United University Club, London, Sept. Zrd, 1906.

\section{THE MEDICO-LEGAL EXPERIENCES OF A GENERAL PRACTITIONER. \\ To the Editors of THE LANCET.}

SIRs,--Though he gets it np for examination purposes the average general practitioner has but few important opportunities during even a long life of work of exercising his medico-legal knowledge. Even if a great or important incident does come in his way the introduction of an "expert" deprives him of much of any credit or glory obtainable. To most of us our medico-legal experiences consist of an occasional inquest which, in the majority of cases, presents no difficulty, medical or legal, and does not require the employ. ment of the coroner's pet pathologist; an occasional lunacy certifying, which does often present some difficulty; and more rarely a police-court case-viz., assault, \&c. Nevertheless, though great occasions are exceptional, minor incidents are not so infrequent in which interesting medicolegal points are involved.

At some time or another nearly every one of us must have been called upon to decide as to the sobriety or otherwise of a given individual, and much may depend on our verdict. The difficulty of decision is often very great and the gradations between "dead drunk" and "had been drinking but was not drunk" are many and subtle. Even the interval between the apprehension of the accused and the appearance of the doctor may have been sufficient to allow of the disappearance or modification of the signs of intoxication. The accused may lighten one's task by admitting to a glass or two, or to having "mixed." The most should be made of such admissions before imposing all those tests of sobriety familiar to the police, for it is possible for the man who has exceeded to pull himself together and neutralise the evidences of alcoholic excess and evade the pitfalls contained in polysyllabic alliterative lingual trials. In all cases the medical examiner should conduct his examination before witnesses, and fortify and support his opinion by the testimony of others whose sobriety should be undoubted. An inquiry into the history of the 